\title{
Tear production and intraocular pressure in canine eyes with corneal ulceration
}

\author{
David L. Williams* and Philippa Burg \\ Department of Veterinary Medicine, University of Cambridge, Madingley Road, Cambridge, CB3 OES, UK
}

\begin{abstract}
This study aimed to evaluate changes in lacrimation and intraocular pressure (IOP) in dogs with unilateral corneal ulceration using the Schirmer tear test (STT) and rebound (TonoVet $\left.{ }^{\circledR}\right)$ tonometry. IOP and STT values were recorded in both ulcerated and non-ulcerated (control) eyes of 100 dogs diagnosed with unilateral corneal ulceration. Dogs presented with other ocular conditions as their primary complaint were excluded from this study. The mean \pm standard deviation for STT values in the ulcerated and control eyes were $20.2 \pm 4.6 \mathrm{~mm} / \mathrm{min}$ and $16.7 \pm 3.5 \mathrm{~mm} / \mathrm{min}$ respectively. The mean \pm standard deviation for IOP in the ulcerated and control eyes were $11.9 \pm 3.1 \mathrm{mmHg}$ and $16.7 \pm 2.6 \mathrm{mmHg}$ respectively. STT values were significantly higher $(\mathrm{p}<0.000001)$ in the ulcerated eye compared to the control eye while IOP was significantly lower $(\mathrm{p}<0.0001)$. There is an increase in lacrimation and a decrease in IOP in canine eyes with corneal ulceration. The higher tear production in ulcerated eyes shows the importance of measuring STT in both eyes in cases of corneal ulceration, since this increased lacrimation may mask an underlying keratoconjunctivitis sicca only evident in the contralateral eye. The lower IOP in ulcerated eyes is likely to relate to mild uveitic change in the ulcerated eye with a concomitant increase in uveoscleral aqueous drainage. While these changes in tear production and IOP in ulcerated eyes are widely recognised in both human and veterinary ophthalmology, it appears that this is the first controlled documented report of these changes in a large number of individuals.
\end{abstract}

Keywords: Corneal ulcer; Dog, Intraocular pressure, Tear production.

\begin{abstract}
Introduction
Despite being widely accepted that corneal ulceration causes an increase in tear production and a decrease in intraocular pressure (IOP) as evidenced by the values from the Schirmer tear test (STT) and tonometric measurements, there appear to be few if any reports documenting these changes in ulcerated eyes in the human or canine population. This study seeks to fill this lacuna in the ophthalmic literature by comparing the tear production and IOP of eyes with ulcerated corneas compared with the control fellow eye in dogs with unilateral corneal ulceration.

The cornea serves a major refractive function while maintaining a protective barrier between the eye and the environment (Gilger et al., 2008). Despite being exposed to environmental hazards, the cornea maintains the integrity of its outer surface by continual replacement of its surface epithelium and through the provision a protective covering of the surface tear-film by the lacrimal glands. Corneal ulceration is one of the most common ocular disorders encountered in veterinary practice and a major cause of ocular pain through exposure of free trigeminal nerve endings in the superficial stroma and blindness either due to excessive scarring or through subsequent perforation of the cornea. (Gilger et al., 2008).
\end{abstract}

Tear secretion is controlled by the lacrimal functional unit consisting of the ocular surface (cornea, conjunctiva, accessory lacrimal glands, and meibomian glands), the main lacrimal gland and the interconnecting innervation (sensory afferent and autonomic efferent nerves) (Stern et al., 2004; Williams, 2008).

The sensory nerves derived from the ophthalmic branch of the trigeminal nerve in the cornea activate the efferent parasympathetic and sympathetic nerves originating in the parasympathetic motor nucleus of the facial nerve but travelling with the trigeminal nerve to the lacrimal gland (Marfurt et al., 2001; Situ and Simpson, 2010). The functional unit regulates the major components of the tear film in order to protect the ocular surface. Painful stimulation of the eye is known to result in tear secretion and other reflexes to prevent the eye from potential damage (Unger, 1990; Belmonte et al., 1997; Situ and Simpson, 2010) but there is little in the literature to show a direct link of increased tear secretion with corneal ulceration.

The IOP occurs through a balance between the production of aqueous humour and its drainage through the iridiocorneal angle (conventional outflow) and through the uveoscleral pathways (unconventional outflow) (Reinstein et al., 2009). 
It has been previously documented that after an initial rise in IOP following ocular surface injury, a prolonged reduction in IOP is usually found (Unger, 1990). An antidromal trigeminal reflex arc is considered to be responsible for this hypotony, predominantly caused by a prostaglandin induced increase in unconventional aqueous outflow (Camras et al., 1977; Fine et al., 2007). Despite this understanding of the mechanism of such a change in IOP there appear to be few is any reports in the literature, just as with tear secretion, to show a direct link between corneal ulceration and decreased IOP in the dog.

\section{Materials and Methods}

This prospective study aims to determine tear production using the STT I method and IOP by rebound tonometry using the TonoVet ${ }^{\circledR}$ (ICare, Helsinki, Finland) in canine eyes with unilateral corneal ulcers to establish the difference in the values between the ulcerated and the fellow control eye. The second eye in the same animal was used as a control to eliminate any diurnal variations of time of sampling or effects of age, gender or weight of the patient (Berger and King, 1998; Gelatt and MacKay, 1998; Hartley et al., 2006).

This study was undertaken over 12 months at the Queen's Veterinary Hospital, Department of Veterinary Medicine, University of Cambridge and at 14 first opinion clinics visited by the senior author in an ambulatory referral clinic. The study was conducted in line with the regulations of the UK Veterinary Surgeons' Act 1966 and was approved by the Ethics and Welfare Committee of the Department of Veterinary Medicine.

One hundred dogs with unilateral corneal ulcers as their presenting complaint were selected for this study in order to compare values between the ulcerated eye and the non-ulcerated fellow eye acting as a control. For each subject, the breed, sex, age, duration and depth of the ulcer were recorded. Any dogs with bilateral corneal ulceration or other conditions as a presenting complaint were excluded as were animals in which either eye had significant additional pathology at presentation.

Corneal ulceration was diagnosed on the basis of a full ocular examination including the use of direct and indirect ophthalmoscopy and slit lamp biomicroscopy, with ulceration confirmed by fluorescein staining undertaken after the STT and IOP values had been obtained. Ulceration was scored as superficial (i.e. a corneal epithelial erosion), mid-stromal (extending no deeper than half stromal thickness, or deep (extending deeper than half the thickness of the stroma) but not including descmetocoeles or perforating corneal lesions. Signs of mild ocular inflammation (conjunctival hyperaemia, aqueous flare, miosis but without profound cellular infiltrative change in the eye) were recorded where present and scored as mild, moderate or severe. Tear production was measured in both eyes using the Schirmer I test which measures aqueous production over one minute in an unanaesthetised eye, therefore measuring basal and reflex tear production (Gelatt et al., 1975). Standard STT strips (Eaglevision ${ }^{\mathrm{TM}}$, Schering-Plough, Memphis TN, USA) with the same batch number were used to measure tear production. IOP was measured in both eyes using the TonoVet $\AA$ rebound tonometer (Icare, Helsinki, Finland) on calibration setting D (used when evaluating iop in the dog) and without the need for topical anaesthesia of the corneal surface (Leiva et al., 2006).

All statistical analyses were undertaken using SPSS v19 (IBM, Armonk, USA). STT and IOP data obeyed the three sigma rule and were thus considered normally distributed, this confirmed using the KolmogorovSmirnov test which yielded values of $Z=1.239$, $P=0.093$ for IOP and $Z=0.886 P=0.413$ for STT. Values for the ulcerated eye were compared with those for the control fellow eye using a Students' $\mathrm{T}$ test with significance deemed to have been reached at $P=0.05$. A cumulative logit model was used to investigate the relationship between STT and IOP and ulcer depth. This model is valuable when analysing ordered categorical data (such as ulcer depth scored as $0,1,2$ or 3 ) with the reduced amount of information that such data sets contain (Lee, 1992).

Each eye was entered as an individual data point, with dog ID included as a subject effect to take nonindependence into account. Ulcer depth was entered as an ordinal variable from 0 (no ulcer) to 3 (deep ulcer), with STT and IOP as covariates. Given the mean value of $20 \pm 3 \mathrm{~mm} / \mathrm{min}$ from normal dogs in one paper from the senior author's research group (Hartley et al., 2006) and $20 \pm 1 \mathrm{~mm} / \mathrm{min}$ in a paper from another group (Giannetto et al., 2009) a power calculation showed that detecting a $3 \mathrm{~mm} / \mathrm{min}$ difference between ulcerated and control eyes with a statistical power of 0.8 and significance at 0.05 would require 30 cases. Similarly detecting a difference of $5 \mathrm{mmHg}$ in dogs with a mean and standard deviation of $19 \pm 6 \mathrm{mmHg}$, a figure derived from a previous published large sample of normal dogs (Giannetto et al., 2009), would require a sample size of 36 dogs. We examined 100 dogs to ensure sufficient power of the study.

\section{Results}

Signalment of cases, ulcer depth and duration, are shown in Table (1). STT results and measurements of IOP for both the ulcerated and the control contralateral eye are given in Table (2) together with scoring of conjunctival hyperaemia, a summatory score of signs of intraocular inflammation (aqueous flare, iris swelling, iris hyperaemia, hypopyon) and degree of miosis, all semi-quantitatively assessed from 0 (not present) to 3 (severe). 
Table 1. Signalment and ulcer characteristics of dogs involved in study.

\begin{tabular}{|c|c|c|c|c|c|}
\hline Case & Breed & Gender & Age & Ulcer duration (days) & Ulcer type \\
\hline 1 & Boxer & fn & 7 & 6 & superficial \\
\hline 2 & CKCS & $\mathrm{mn}$ & 13 & 14 & mid stromal \\
\hline 3 & Cross bred & me & 12 & 21 & mid stromal \\
\hline 4 & Cocker spaniel & $\mathrm{mn}$ & 5 & 1 & superficial \\
\hline 5 & WHWT & $\mathrm{mn}$ & 12 & 21 & mid stromal \\
\hline 6 & Shih Tzu & $\mathrm{mn}$ & 5 & 14 & superficial \\
\hline 7 & Labrador retriever & me & 0.2 & 2 & deep stromal \\
\hline 8 & Pug & fe & 0.8 & 3 & deep stromal \\
\hline 9 & French bulldog & fe & 4 & 21 & superficial \\
\hline 10 & French bulldog & me & 6 & 12 & superficial \\
\hline 11 & Boxer & me & 5 & 7 & superficial \\
\hline 12 & Jack Russell terrier & me & 8 & 21 & superficial \\
\hline 13 & English springer spaniel & me & 7 & 14 & mid stromal \\
\hline 14 & Boxer & me & 12 & 7 & superficial \\
\hline 15 & Pug & fn & 8 & 4 & mid stromal \\
\hline 16 & Pug & fe & 0.8 & 2 & pinpoint mid stromal \\
\hline 17 & Boxer & $\mathrm{mn}$ & 8 & 14 & superficial \\
\hline 18 & Cross bred & $\mathrm{mn}$ & 7 & 12 & superficial \\
\hline 19 & English springer spaniel & $\mathrm{mn}$ & 8 & 21 & superficial \\
\hline 20 & Pug & fe & 6 & 10 & pinpoint mid-stromal \\
\hline 21 & Pug & fn & 7 & 7 & central mid stromal \\
\hline 22 & Cross bred & $\mathrm{mn}$ & 9 & 7 & superficial \\
\hline 23 & German shepherd dog & $\mathrm{mn}$ & 11 & 14 & superficial \\
\hline 24 & Cairn terr & fn & 13 & 21 & superficial \\
\hline 25 & Yorkshire terrier & $\mathrm{mn}$ & 12 & 7 & superficial \\
\hline 26 & Yorkshire terrier & $\mathrm{mn}$ & 11 & 7 & mid stromal \\
\hline 27 & CKCS & fn & 11 & 7 & superficial \\
\hline 28 & Cross bred & fn & 10 & 21 & mid stromal \\
\hline 29 & Yorkshire terrier & fn & 11 & 7 & superficial \\
\hline 30 & Boxer & $\mathrm{mn}$ & 12 & 21 & superficial \\
\hline 31 & CKCS & fn & 8 & 7 & punctuate mid-stromal \\
\hline 32 & Pug & $\mathrm{mn}$ & 6 & 5 & superficial \\
\hline 33 & SBT & $\mathrm{mn}$ & 6 & 21 & superficial \\
\hline 34 & Pug & $\mathrm{mn}$ & 4 & 5 & superficial \\
\hline 35 & Boxer & me & 8 & 6 & superficial \\
\hline 36 & Shih-tzu & $\mathrm{mn}$ & 5.5 & 14 & superficial \\
\hline 37 & SBTx & $\mathrm{mn}$ & 9 & 7 & superficial \\
\hline 38 & Boxer & fn & 7.5 & 10 & superficial \\
\hline 39 & Cross bred & fn & 1.5 & 4 & superficial \\
\hline 40 & Boxer & fn & 10 & 21 & superficial \\
\hline 41 & SBT & fn & 8 & 28 & superficial \\
\hline 42 & Boxer & $\mathrm{mn}$ & 8 & 21 & superficial \\
\hline 43 & Yorkshire terrier & fn & 10 & 28 & superficial \\
\hline 44 & CKCS & fn & 10 & 28 & superficial \\
\hline 45 & Sharpei & $\mathrm{mn}$ & 3 & 14 & superficial \\
\hline 46 & Boxer & fn & 10 & 21 & superficial \\
\hline 47 & SBT & fn & 8 & 28 & superficial \\
\hline 48 & SBT & $\mathrm{mn}$ & 7.6 & 100 & deep stromal \\
\hline 49 & Pug & fn & 6 & 14 & mid stromal \\
\hline 50 & Cross bred & me & 12 & 7 & superficial \\
\hline 51 & WHWT & Fn & 8 & 28 & sup epith + KCS \\
\hline 52 & Pug & $\mathrm{Fe}$ & 7.6 & 100 & deep stromal \\
\hline
\end{tabular}


Table 1. Signalment and ulcer characteristics of dogs involved in study (Cont.).

\begin{tabular}{|c|c|c|c|c|c|}
\hline Case & Breed & Gender & Age & Ulcer duration (days) & Ulcer type \\
\hline 53 & Cross-bred & $\mathrm{Mn}$ & 6 & 14 & mid stromal \\
\hline 54 & Boxer & $\mathrm{Mn}$ & 12 & 7 & sup ep \\
\hline 55 & Cross-bred & Fn & 13 & 7 & mid stromal \\
\hline 56 & CKCS & $\mathrm{Fe}$ & 7 & 14 & mid stromal \\
\hline 57 & Boxer & $\mathrm{Mn}$ & 8 & 21 & superficial \\
\hline 58 & SBT & Fn & 10 & 14 & mid stromal \\
\hline 59 & Boxer & $\mathrm{Mn}$ & 4 & 10 & superficial \\
\hline 60 & Pug & Fn & 2 & 10 & mid stromal \\
\hline 61 & Boxer X & $\mathrm{Me}$ & 9 & 7 & superficial \\
\hline 62 & Bulldog & $\mathrm{Me}$ & 4 & 21 & superficial \\
\hline 63 & Labrador & $\mathrm{Mn}$ & 7 & 21 & mid stromal \\
\hline 64 & Boxer & $\mathrm{Mn}$ & 8 & 28 & superficial \\
\hline 65 & Chihuahua & Fn & 3 & 12 & mid stromal \\
\hline 66 & Lhasa Apso & Fn & 5 & 14 & mid stromal \\
\hline 67 & Sharpei & $\mathrm{Fe}$ & 6 & 7 & superficial \\
\hline 68 & Yorkshire terrier & $\mathrm{Mn}$ & 4 & 5 & deep stromal \\
\hline 69 & Boxer & $\mathrm{Mn}$ & 8 & 12 & superficial \\
\hline 70 & Boxer & $\mathrm{Mn}$ & 7 & 21 & superficial \\
\hline 71 & Cross bred & $\mathrm{Me}$ & 9 & 28 & superficial \\
\hline 72 & Chihuahua & Fn & 10 & 5 & superficial \\
\hline 73 & Boxer cross & $\mathrm{Mn}$ & 11 & 14 & superficial \\
\hline 74 & Pug & Mn & 5 & 7 & deep stromal \\
\hline 75 & Cross-bred & $\mathrm{Me}$ & 12 & 14 & superficial \\
\hline 76 & Rotweiler & Fn & 7 & 5 & deep stromal \\
\hline 77 & Miniature Schnauzer & $\mathrm{Fe}$ & 6 & 7 & superficial \\
\hline 78 & Lhasa Apso & $\mathrm{Fe}$ & 7 & 7 & superficial \\
\hline 79 & German Shepherd dog & $\mathrm{Mn}$ & 12 & 14 & superficial \\
\hline 80 & Short-haired pointer & $\mathrm{Mn}$ & 9 & 21 & superficial \\
\hline 81 & Boxer & $\mathrm{Mn}$ & 8 & 35 & superficial \\
\hline 82 & Cross-bred & Fn & 6 & 14 & deep stromal \\
\hline 83 & Finnish laphund & Fn & 4 & 10 & deep stromal \\
\hline 84 & CKCS & $\mathrm{Fe}$ & 6 & 6 & deep stromal \\
\hline 85 & Cocker spaniel & Fn & 12 & 35 & superficial \\
\hline 86 & Pembroke Corgi & $\mathrm{Me}$ & 6 & 5 & mid stromal \\
\hline 87 & Boxer & $\mathrm{Mn}$ & 8 & 21 & superficial \\
\hline 88 & Pekingese & $\mathrm{Me}$ & 5 & 2 & deep stromal \\
\hline 89 & Cross-bred & $\mathrm{Fe}$ & 6 & 28 & superficial \\
\hline 90 & Boxer & $\mathrm{Mn}$ & 8 & 21 & superficial \\
\hline 91 & French bulldog & Mn & 5 & 21 & deep stromal \\
\hline 92 & Cross-bred & $\mathrm{Fe}$ & 7 & 28 & superficial \\
\hline 93 & Dalmatian & Fn & 9 & 12 & superficial \\
\hline 94 & Alaskan Malamute & Fn & 7 & 18 & superficial \\
\hline 95 & WHWT & $\mathrm{Mn}$ & 8 & 21 & superficial \\
\hline 96 & English Springer spaniel & $\mathrm{Mn}$ & 9 & 25 & superficial \\
\hline 97 & Boxer & Fn & 8 & 12 & superficial \\
\hline 98 & Yorkshire terrier & Fn & 5 & 18 & superficial \\
\hline 99 & German shepherd dog & Fn & 8 & 14 & superficial \\
\hline 100 & Boxer & $\mathrm{Me}$ & 12 & 56 & superficial \\
\hline
\end{tabular}


Table 2. Intraocular pressure (IOP) and tear production measured at Schirmer tear test (STT) in ulcerated eye and normal fellow eye together with clinical data on presence (1) or absence (0) of ocular hyperaemia, clinical signs of inflammation and miosis.

\begin{tabular}{|c|c|c|c|c|c|c|c|}
\hline Case & $\begin{array}{c}\text { IOP ulcerated } \\
\text { eye }\end{array}$ & $\begin{array}{c}\text { IOP normal } \\
\text { eye }\end{array}$ & $\begin{array}{c}\text { STT ulcerated } \\
\text { eye }\end{array}$ & $\begin{array}{c}\text { STT normal } \\
\text { eye }\end{array}$ & $\begin{array}{l}\text { Conjunctival } \\
\text { hyperaemia }\end{array}$ & $\begin{array}{c}\text { Intraocular } \\
\text { inflammation }\end{array}$ & Miosis \\
\hline 1 & 14 & 17 & 19 & 16 & 0 & 0 & 0 \\
\hline 2 & 9 & 14 & 22 & 18 & 0 & 0 & 1 \\
\hline 3 & 13 & 18 & 19 & 15 & 0 & 0 & 0 \\
\hline 4 & 10 & 21 & 21 & 14 & 0 & 0 & 3 \\
\hline 5 & 7 & 13 & 22 & 19 & 0 & 0 & 0 \\
\hline 6 & 13 & 14 & 16 & 10 & 0 & 0 & 0 \\
\hline 7 & 7 & 15 & 25 & 23 & 1 & 1 & 1 \\
\hline 8 & 8 & 16 & 10 & 14 & 1 & 1 & 1 \\
\hline 9 & 12 & 16 & 17 & 16 & 0 & 0 & 0 \\
\hline 10 & 8 & 13 & 22 & 17 & 0 & 0 & 0 \\
\hline 11 & 12 & 18 & 24 & 19 & 0 & 0 & 0 \\
\hline 12 & 13 & 15 & 27 & 22 & 1 & 0 & 0 \\
\hline 13 & 12 & 17 & 24 & 20 & 1 & 0 & 1 \\
\hline 14 & 14 & 16 & 22 & 19 & 0 & 0 & 0 \\
\hline 15 & 8 & 13 & 24 & 17 & 0 & 0 & 1 \\
\hline 16 & 10 & 15 & 22 & 19 & 0 & 0 & 1 \\
\hline 17 & 12 & 15 & 26 & 23 & 0 & 0 & 0 \\
\hline 18 & 14 & 18 & 15 & 13 & 0 & 0 & 0 \\
\hline 19 & 12 & 22 & 24 & 19 & 1 & 0 & 0 \\
\hline 20 & 13 & 16 & 14 & 16 & 0 & 0 & 0 \\
\hline 21 & 9 & 16 & 18 & 14 & 0 & 0 & 1 \\
\hline 22 & 12 & 15 & 19 & 15 & 1 & 0 & 0 \\
\hline 23 & 9 & 15 & 22 & 18 & 1 & 0 & 0 \\
\hline 24 & 12 & 17 & 19 & 15 & 1 & 0 & 0 \\
\hline 25 & 8 & 16 & 22 & 17 & 1 & 0 & 0 \\
\hline 26 & 18 & 21 & 24 & 9 & 1 & 0 & 0 \\
\hline 27 & 15 & 17 & 20 & 12 & 1 & 1 & 0 \\
\hline 28 & 11 & 15 & 18 & 15 & 1 & 0 & 1 \\
\hline 29 & 13 & 14 & 14 & 11 & 1 & 1 & 0 \\
\hline 30 & 4 & 11 & 22 & 16 & 0 & 0 & 0 \\
\hline 31 & 4 & 11 & 0 & 12 & 0 & 0 & 0 \\
\hline 32 & 15 & 9 & 19 & 8 & 0 & 0 & 0 \\
\hline 33 & 12 & 15 & 24 & 6 & 1 & 0 & 0 \\
\hline 34 & 15 & 11 & 28 & 9 & 0 & 0 & 0 \\
\hline 35 & 13 & 25 & 20 & 27 & 0 & 0 & 0 \\
\hline 36 & 12 & 18 & 17 & 14 & 0 & 0 & 0 \\
\hline 37 & 15 & 13 & 19 & 23 & 0 & 0 & 0 \\
\hline 38 & 13 & 23 & 15 & 13 & 0 & 0 & 0 \\
\hline 39 & 13 & 17 & 15 & 7 & 0 & 0 & 0 \\
\hline 40 & 12 & 17 & 22 & 16 & 0 & 0 & 0 \\
\hline 41 & 17 & 15 & 13 & 17 & 0 & 0 & 0 \\
\hline 42 & 9 & 24 & 18 & 21 & 1 & 1 & 0 \\
\hline 43 & 14 & 15 & 22 & 20 & 0 & 0 & 0 \\
\hline 44 & 15 & 16 & 18 & 15 & 0 & 0 & 0 \\
\hline 45 & 11 & 15 & 32 & 21 & 0 & 0 & 0 \\
\hline 46 & 27 & 14 & 18 & 22 & 1 & 0 & 1 \\
\hline 47 & 12 & 15 & 0 & 15 & 1 & 1 & 0 \\
\hline 48 & 10 & 20 & 22 & 18 & 1 & 0 & 0 \\
\hline 49 & 7 & 14 & 22 & 18 & 1 & 1 & 1 \\
\hline 50 & 15 & 21 & 18 & 14 & 0 & 0 & 0 \\
\hline 51 & 14 & 16 & 19 & 16 & 0 & 0 & 0 \\
\hline 52 & 12 & 16 & 15 & 13 & 1 & 1 & 1 \\
\hline
\end{tabular}


Table 2. Intraocular pressure (IOP) and tear production measured at Schirmer tear test (STT) in ulcerated eye and normal fellow eye together with clinical data on presence (1) or absence (0) of ocular hyperaemia, clinical signs of inflammation and miosis (Cont.).

\begin{tabular}{|c|c|c|c|c|c|c|c|}
\hline Case & $\begin{array}{c}\text { IOP ulcerated } \\
\text { eye }\end{array}$ & $\begin{array}{c}\text { IOP normal } \\
\text { eye }\end{array}$ & $\begin{array}{l}\text { STT ulcerated } \\
\text { eye }\end{array}$ & $\begin{array}{c}\text { STT normal } \\
\text { eye }\end{array}$ & $\begin{array}{c}\text { Conjunctival } \\
\text { hyperaemia }\end{array}$ & $\begin{array}{l}\text { Intraocular } \\
\text { inflammation }\end{array}$ & Miosis \\
\hline 53 & 13 & 18 & 20 & 17 & 1 & 1 & 1 \\
\hline 54 & 11 & 16 & 21 & 17 & 0 & 0 & 0 \\
\hline 55 & 12 & 18 & 18 & 16 & 1 & 0 & 0 \\
\hline 56 & 11 & 17 & 19 & 17 & 1 & 0 & 1 \\
\hline 57 & 12 & 15 & 22 & 18 & 1 & 0 & 1 \\
\hline 58 & 13 & 20 & 21 & 16 & 0 & 0 & 1 \\
\hline 59 & 11 & 16 & 18 & 15 & 0 & 0 & 0 \\
\hline 60 & 14 & 16 & 18 & 17 & 0 & 0 & 0 \\
\hline 61 & 12 & 17 & 16 & 16 & 0 & 1 & 0 \\
\hline 62 & 13 & 19 & 19 & 18 & 1 & 1 & 0 \\
\hline 63 & 13 & 18 & 22 & 18 & 1 & 0 & 0 \\
\hline 64 & 10 & 16 & 18 & 19 & 0 & 0 & 0 \\
\hline 65 & 14 & 16 & 26 & 22 & 0 & 1 & 1 \\
\hline 66 & 15 & 18 & 21 & 18 & 0 & 0 & 0 \\
\hline 67 & 13 & 16 & 25 & 21 & 1 & 0 & 0 \\
\hline 68 & 13 & 17 & 27 & 17 & 0 & 0 & 1 \\
\hline 69 & 13 & 18 & 24 & 21 & 1 & 0 & 0 \\
\hline 70 & 8 & 14 & 18 & 18 & 1 & 0 & 0 \\
\hline 71 & 13 & 16 & 24 & 23 & 1 & 1 & 0 \\
\hline 72 & 7 & 17 & 17 & 16 & 0 & 1 & 0 \\
\hline 73 & 14 & 17 & 19 & 15 & 0 & 1 & 1 \\
\hline 74 & 12 & 18 & 22 & 17 & 1 & 0 & 1 \\
\hline 75 & 15 & 18 & 24 & 18 & 0 & 0 & 0 \\
\hline 76 & 13 & 17 & 21 & 18 & 0 & 0 & 0 \\
\hline 77 & 14 & 19 & 27 & 21 & 1 & 0 & 0 \\
\hline 78 & 7 & 19 & 22 & 18 & 0 & 1 & 0 \\
\hline 79 & 6 & 17 & 19 & 17 & 0 & 1 & 1 \\
\hline 80 & 8 & 19 & 19 & 16 & 0 & 1 & 1 \\
\hline 81 & 13 & 17 & 15 & 13 & 0 & 1 & 1 \\
\hline 82 & 11 & 19 & 20 & 17 & 1 & 0 & 0 \\
\hline 83 & 14 & 19 & 26 & 19 & 1 & 0 & 0 \\
\hline 84 & 7 & 20 & 22 & 16 & 1 & 0 & 0 \\
\hline 85 & 14 & 18 & 21 & 19 & 0 & 1 & 1 \\
\hline 86 & 12 & 18 & 23 & 15 & 1 & 0 & 0 \\
\hline 87 & 8 & 18 & 25 & 19 & 0 & 0 & 0 \\
\hline 88 & 13 & 15 & 22 & 15 & 1 & 1 & 1 \\
\hline 89 & 13 & 19 & 24 & 19 & 0 & 0 & 0 \\
\hline 90 & 14 & 17 & 22 & 17 & 0 & 0 & 0 \\
\hline 91 & 12 & 18 & 25 & 21 & 0 & 0 & 0 \\
\hline 92 & 10 & 15 & 17 & 13 & 1 & 0 & 0 \\
\hline 93 & 12 & 16 & 19 & 17 & 0 & 0 & 0 \\
\hline 94 & 13 & 15 & 21 & 16 & 0 & 0 & 0 \\
\hline 95 & 12 & 17 & 22 & 17 & 1 & 0 & 0 \\
\hline 96 & 14 & 17 & 18 & 14 & 0 & 0 & 0 \\
\hline 97 & 8 & 16 & 19 & 18 & 1 & 1 & 0 \\
\hline 98 & 9 & 15 & 21 & 19 & 0 & 1 & 1 \\
\hline 99 & 13 & 18 & 18 & 16 & 0 & 1 & 0 \\
\hline 100 & 14 & 17 & 22 & 17 & 1 & 0 & 0 \\
\hline
\end{tabular}


The mean ( \pm standard deviation) of STT values are shown in Table (3) and the mean ( \pm standard deviation) of IOP values are shown in Table (4). Both tables also show the values for eyes with superficial, mid stromal and deep stromal corneal ulcers and significance of differences between ulcerated and control eyes.

Table 3. Mean \pm Standard Deviation of Schirmer tear test (STT) values in the ulcerated and non-ulcerated eyes categorised according to the depth of the ulcer as superficial, mid stromal or deep and significance of difference in STT between ulcerated and normal eyes.

\begin{tabular}{lccc}
\hline \multirow{2}{*}{ Category } & \multicolumn{2}{c}{$\begin{array}{c}\text { Mean } \pm \text { Standard Deviation } \\
\text { STT }(\mathrm{mm} / \mathrm{min})\end{array}$} & $\begin{array}{c}\text { Significance } \\
\text { of } \\
\text { difference }\end{array}$ \\
\cline { 2 - 3 } & Ulcerated & Non-ulcerated & \\
\hline $\begin{array}{l}\text { All ulcers } \\
(100)\end{array}$ & $20.8 \pm 4.6$ & $16.7 \pm 3.5$ & $\mathrm{P}<0.000001$ \\
$\begin{array}{l}\text { Superficial } \\
(68)\end{array}$ & $20.2 \pm 5.1$ & $16.6 \pm 6.2$ & $\mathrm{p}<0.0001$ \\
$\begin{array}{l}\text { Mid Stromal } \\
(18)\end{array}$ & $19.9 \pm 2.9$ & $16.4 \pm 3.27$ & $\mathrm{p}<0.001$ \\
Deep (13) & $19.0 \pm 7.9$ & $16.7 \pm 3.9$ & $\mathrm{p}<0.001$ \\
\hline
\end{tabular}

Table 4. Mean \pm Standard Deviation of intraocular pressure (IOP) values in the ulcerated and non-ulcerated eyes categorised according to the depth of the ulcer as superficial, mid stromal or deep and significance of difference in IOP between ulcerated and normal eyes.

\begin{tabular}{lccc}
\hline \multirow{2}{*}{ Category } & \multicolumn{2}{c}{$\begin{array}{c}\text { Mean } \pm \text { Standard Deviation } \\
\text { IOP }(\mathrm{mmHg})\end{array}$} & $\begin{array}{c}\text { Significance } \\
\text { of } \\
\text { difference }\end{array}$ \\
\cline { 2 - 3 } & Ulcerated & Normal & \\
\cline { 1 - 2 } $\begin{array}{l}\text { All Ulcers } \\
\text { (50) }\end{array}$ & $12.8 \pm 7.7$ & $16.1 \pm 3.3$ & $\mathrm{p}<0.0001$ \\
$\begin{array}{l}\text { Superficial } \\
(37)\end{array}$ & $12.7 \pm 2.8$ & $16.6 \pm 2.7$ & $\mathrm{p}<0.00001$ \\
$\begin{array}{l}\text { Mid Stromal } \\
(10)\end{array}$ & $14.1 \pm 3.8$ & $16.2 \pm 2.2$ & $\mathrm{p}<0.0001$ \\
Deep (3) & $7.9 \pm 1.1$ & $17.0 \pm 1.9$ & $\mathrm{p}<0.0001$ \\
\hline
\end{tabular}

Mean ( \pm standard deviation) STT values in the ulcerated eye compared to the non-ulcerated fellow eye were $20.8 \pm 4.6$ and $16.7 \pm 3.5$ respectively, this difference being highly statistically significant at $\mathrm{p}<0.000001$. Mean ( \pm standard deviation) values for IOP in the ulcerated eye compared to the control eye were $11.8 \pm 3.0 \mathrm{mmHg}$ and $16.7 \pm 2.6 \mathrm{mmHg}$ respectively, these being statistically significantly different at $P=0.0001$. Both IOP and STT were significant predictors of ulcer depth, with IOP significantly different at $x^{2}$ (chi squared) $=11.25$ p $<0.00001$ and STT significantly different at $x^{2}$ (chi squared $)=8.28 \mathrm{p}<0.00001$. Variations in duration of ulceration did not predict differences in IOP or STT.

\section{Discussion}

The results of this study show an increased tear production and decreased IOP to occur in eyes with corneal ulceration in the dog. An increase in tear production has been noted in the literature with reference to ocular pain (Belmonte et al., 1997). One previous paper has documented that the STT in dogs with corneal epithelial defects is significantly greater when compared to the contralateral unaffected eyes (Murphy et al., 2001), a result confirmed in this study, but in that report the change in tear production was but a marginal note in a larger study of superficial epithelial erosions: here we extend the investigation to a greater number of ulcerated eyes with ulcers of different types and depths. The most likely cause of increased tear production in corneal ulceration is the interaction of corneal nociceptive stimulation and subsequent lacrimal secretion (Unger, 1990).

The cornea is one of the most richly innervated tissues in the body receiving dense innervation by sensory nerves predominantly originating from neurons located in the ipsilateral trigeminal ganglion and modest sympathetic innervation from the superior cervical ganglion. The peripheral axons of the neurons terminate throughout the corneal epithelium as free nerve endings (Marfurt et al., 2001). A previous study investigating the relationship between the stimulation of corneal sensory nerves and efferent output of the lacrimal functional unit determined by tear secretion showed that tear secretion increased almost linearly with the increase of stimulus intensity (Situ and Simpson, 2010). When noxious stimuli activate sensory afferents in the functional unit, a series of co-ordinated reflexes, including reflex tearing, are triggered to protect the eye from potential damage.

The current study supports previous findings that ocular pain, in this case resulting from corneal ulceration, will cause an increase in tear production due to stimulation of the lacrimal functional unit. It is possible that noxious stimuli causing the ulceration were also responsible for generating inflammation, but the ulcerated eyes did not show clinical signs of marked external inflammation which one would expect were this to be the cause of the changes in tear production and hypotony. There were no significant differences between eyes with signs of mild inflammation, as noted above, and those without.

The study makes the assumption that there is no significant difference in STT or IOP between the right and left eyes, this based on the fact that previous studies have not shown a difference between STT values of left and right eyes in normal dogs (Wyman et al., 1995), and similarly IOP values have not been shown to differ between eyes (Giannetto et al., 2009) so we feel confident that differences between ulcerated and control eyes here are highly likely to be related to the ulceration and not a random difference between eyes. One limitation of this study was to only perform the Schirmer I test which measures both basal and reflex tear production. Further studies could evaluate use of the Schirmer II test to measure changes in basal tear 
production in corneal ulceration, by eliminating reflex tear production. It might also be argued that for completeness the study should have evaluated the ocular aqueous outflow tract by gonioscopy, but since IOP was normal or reduced and not increased in these eyes, such an additional diagnostic step was not considered essential. It will be noted that a significant number of animals (24\%) had one or both eyes in which the STT was less than $15 \mathrm{~mm} / \mathrm{min}$. While impossible to prove with the current data set, it is conceivable that animals with subnormal tear production are predisposed to corneal ulceration; such a hypothesis would merit further study evaluating STT values in age and breed-matched populations with and without corneal ulceration. A decrease in IOP is well recognised in association with ocular inflammation (Fine et al., 2007) but not previously associated with corneal ulceration in dogs, or indeed in any other species to these authors' knowledge. It has been noted above that IOP is formed due to a balance between the production of aqueous humour and its drainage through the uveoscleral outflow and iridocorneal angle.

Prostaglandins (PGs) are regarded as mediators of the inflammatory process and are also present in ocular tissues. Studies have shown that during ocular inflammation PG concentration in the aqueous humour is higher than that found in normal aqueous humour (Camras et al., 1977). It has been shown that PGs reduce IOP in a number of animal species including dogs, cats, nonhuman primates and rabbits by increasing uveoscleral aqueous humour outflow (Nilsson et al., 1989; Weinreb et al., 2002).

Thus we postulate that the trigeminal antidromic reflex occurring after exposure of free stromal and intraepithelial nerve endings following corneal ulceration results in a prostaglandin production in the anterior segment of the eye, increased unconventional aqueous outflow and a hypotony, as demonstrated in the majority of cases here. It is conceivable that changes in the ulcerated cornea such as corneal oedema alter the elasticity of the tissues and thus invalidate the rebound tonometry but recent studies suggest that such changes are small and not clinically significant (Smedowski et al., 2014). The present study documents that corneal ulceration in the dog is associated with an increase in tear production and a decrease in IOP. We would suggest that the ulceration is a cause of increased lacrimation through trigeminal stimulation and reduced IOP through prostaglandin-related increase in uveoscleral outflow, but clearly these postulates cannot be proven in such an observational study. This would require an experimental protocol in which corneal ulceration was caused and lacrimation and unconventional outflow measured before and after ocular surface injury. The welfare compromise of animals used in such an investigation would be considerable and would preclude it under UK law, but we hope that this study on eyes with spontaneous corneal ulceration has provided useful data on the ocular changes associated with corneal ulceration.

This study shows the importance of measuring tear production in both eyes of dogs with corneal ulceration since the higher tear production in the ulcerated eye may produce an apparently normal STT reading and mask an underlying case of KCS. In the cuirrent series of animals cases $6,18,21,26,27,29,31,32,33,34$ and 39 all had suboptimal STT values in the normal eye although the raised STT in the ulcerated eye would have made it appear that they did not have any deficit in tear production if only that eye had been tested. It is impossible to know if a low tear production was involved in the development of ulceration before trigeminal stimulation in the ulcerated cornea increased the STT but we consider that this may be possible. The reduction in IOP suggests a mild intraocular inflammatory process in many if not all eyes with corneal ulceration which should be documented by tonometry in any eye with an ulcerated cornea and addressed therapeutically if severe. Many facts in veterinary ophthalmology, as in many other areas of veterinary medicine, are widely accepted but without any firm data to back them up. That eyes with corneal ulceration have increased lacrimation and decreased IOP is one of these unquestioned truths. It is hoped that this study has provided some evidence to support these assumptions and also suggested areas of further research to elucidate the mechanisms by which these ocular changes occur.

\section{Conflict of interest:}

The authors declare that there is no conflict of interest.

\section{References}

Belmonte, C., Garcia-Hirschfield, J. and Gallar, J. 1997. Neurobiology of ocular pain. Prog. Retin. Eye Res. 16, 117-156.

Berger, S.L. and King, V.L. 1998. The fluctuation of tear production. J. Am. Anim. Hosp. Assoc. 34(1), 79-83.

Camras, C.B., Bito, L.Z. and Eakins, K.E. 1977. Reduction of intraocular pressure by prostaglandins applied topically to the eyes of conscious rabbits. Invest. Ophthalmol. Vis. Sci. 16(12), 1125-1134.

Fine, H.F., Biscette, O., Chang, S. and Schiff, W.M. 2007. Ocular hypotony: a review. Compr. Ophthalmol. Update 8(1), 29-37.

Gelatt, K.N., Peiffer, R.L., Erickson, J.L. and Gum, G.G. 1975. Evaluation of tear formation in the dog, using a modification of the Schirmer tear test. J. Am. Vet. Med. Assoc. 166(4), 368-370.

Gelatt, K.N. and MacKay, E.O. 1998. Distribution of intraocular pressure in dogs. Vet. Ophthalmol. 1(23), 109-114. 
Giannetto, C., Piccione, G. and Giudice, E. 2009. Daytime profile of the intraocular pressure and tear production in normal dog. Vet. Ophthalmol. 12(5), 302-305.

Gilger, B.C., Ollivier, F.J. and Bentley, E. 2008. Diseases and surgery of the canine cornea and sclera. In: Essentials of veterinary ophthalmology, $2^{\text {nd }}$ edn (ed. Gelatt KN). Blackwell Publishing, Iowa, pp: 119-154.

Hartley, C., Williams, D.L. and Adams, V.J. 2006. Effect of age, gender, weight, and time of day on tear production in normal dogs. Vet. Ophthalmol. 9(1), 53-57.

Lee, J. 1992. Cumulative logit modelling for ordinal response variables: applications to biomedical research. Comput. Appl. Biosci. 8(6), 555-562.

Leiva, M., Naranjo, C. and Peña, M.T. 2006. Comparison of the rebound tonometer (ICare) to the applanation tonometer (Tonopen XL) in normotensive dogs. Vet. Ophthalmol. 9(1), 17-21.

Marfurt, C.F., Murphy, C.J. and Florczak, J.L. 2001. Morphology and neurochemistry of canine corneal innervation. Invest. Ophthalmol. Vis. Sci. 42(10), 2242-2251.

Murphy, C.J., Marfurt, C.F., McDermott, A., Bentley, E., Abrams, G.A., Reid, T.W. and Cambell, S. 2001. Spontaneous chronic corneal epithelial defects (SCCED) in dogs: Clinical features, innervation, and effect of topical SP, with or without IGF-1.
Invest. Ophthalmol. Vis. Sci. 42(10), 2252-2261.

Nilsson, S.F., Samuelson, M., Bill, A. and Stjernschantz, J. 1989. Increased uveoscleral outflow as a possible mechanism of ocular hypotension caused by prostaglandin F2 $\alpha-1-$ isopropylester in the Cynomolgus monkey. Exp. Eye Res. 48(5), 707-716.

Reinstein, S., Rankin, A. and Allbaugh, R. 2009. Canine glaucoma: pathophysiology and diagnosis. Compend. Contin. Educ. Vet. 31(10), 450-452.

Situ, P. and Simpson, T.L. 2010. Interaction of corneal nociceptive stimulation and lacrimal secretion. Invest. Ophthalmol. Vis. Sci. 51(11), 5640-5645.

Stern, M.E., Gao, J., Siemasko, K.F., Beuerman, R.W. and Pflugfeilder, S.C. 2004. The role of the lacrimal functional unit in the pathophysiology of dry eye. Exp. Eye Res. 78(3), 409-416.

Unger, W.G. 1990. Mediation of the ocular response to injury. J. Ocul. Pharmacol. 6(4), 337-353.

Weinreb, R.N., Toris, C.B., Gabelt, B.'A.T., Linsey, J.D. and Kaufman, P.L. 2002. Effects of prostaglandins on the aqueous humor outflow pathway. Surv. Ophthalmol. 47(Suppl. 1), S53-64.

Williams, D.L. 2008. Immunopathogenesis of keratoconjunctivitis sicca in the dog. Vet. Clin. North Am. Small Anim. Pract. 38(2), 251-268.

Wyman, M., Gilger, B., Mueller, P., Norrýs, K., 1995. Clinical evaluation of a new Schirmer tear test in the dog. Vet. Comp. Ophthalmol. 5, 211-214. 